Article

\title{
Advanced Modelling Tools to Support Planning for Sand/Gravel Quarries
}

\author{
Filippo Carlo Pavesi * (D), Anna Richiedei (D) and Michele Pezzagno (D) \\ Department of Civil Engineering, Architecture, Land, Environment and of Mathematics, DICATAM, \\ University of Brescia, via Branze 43, 25123 Brescia, Italy; anna.richiedei@unibs.it (A.R.); \\ michele.pezzagno@unibs.it (M.P.) \\ * Correspondence: filippo.pavesi@unibs.it; Tel.: +39-030-3711268
}

check for

updates

Citation: Pavesi, F.C.; Richiedei, A.; Pezzagno, M. Advanced Modelling Tools to Support Planning for Sand/Gravel Quarries. Sustainability 2021, 13, 6380. https://doi.org/ $10.3390 /$ su13116380

Academic Editors:

Beniamino Murgante,

Federico Amato, Lorena Fiorini, Alessandro Marucci and Sabrina Lai

Received: 29 April 2021

Accepted: 31 May 2021

Published: 4 June 2021

Publisher's Note: MDPI stays neutral with regard to jurisdictional claims in published maps and institutional affiliations.

Copyright: (C) 2021 by the authors. Licensee MDPI, Basel, Switzerland. This article is an open access article distributed under the terms and conditions of the Creative Commons Attribution (CC BY) license (https:// creativecommons.org/licenses/by/ $4.0 /)$.

\begin{abstract}
Sand and gravel quarry planning must guarantee the public interest in the procurement of raw materials while ensuring environmental sustainability. An Analyzing Planning Support System for sand and gravel quarry plan can assist decision-makers during the planning process. The proposed Analyzing PSS uses integrating geologic, economic, environmental, and geographic information to quantify raw materials and the size of quarries. This kind of tool is useful to support public authority decisions. The study provides the results of an experience conducted in the province of Brescia (NUT 3 in Northern Italy).
\end{abstract}

Keywords: quarrying; multicriterial analysis approach; geographic information system; spatial planning support system; decision support; reward system; sand and gravel

\section{Introduction}

Sand and gravel quarrying is needed to obtain natural raw materials mainly used by the construction sector, and it is a strategic activity for the economy. This activity is conditioned both by the presence of raw materials in the subsoil and by sites' accessibility and suffers market pressures caused by the demand for the material. Quarrying causes strong environmental impacts and must be limited, mitigated, and compensated as much as possible. Natural aggregate materials (i.e., sand and gravel) are considered "the most consumed bulk product in the world after water" [1] and, although the use of recycled aggregate is promising [2], the worldwide primary sand/gravel production is estimated to grow in the next decades [3]. Worldwide sand and gravel excavation is not monitored, and the use of aggregates is strictly correlated to cement production [4]. In the European Union there was a decline of raw material needs due to the economic crisis of the construction sector in 2008. The raw material needs increased again from 2013 to 2018 when the total production of aggregates was estimated at 2.894 million tons, of which 1.135 million tons was sand and gravel [5].

Administration authorities are called upon to govern the aggregate quarrying process, considering its multiple (and sometimes conflicting) dimensions, such as the economic and environmental ones. In civil society, stakeholders hold contradictory theses, as there is a public interest both in the procurement of raw materials and in environmental protection. Sand and gravel quarry planning tackles all the dimensions of the quarrying process, building an integrated system of information and (geo)data, developing specific strategies, and establishing rules. Although authorities have to make complex decisions during the quarry planning process, there is a lack of objective tools to turn the planning goals into possible scenarios related to the strategy.

Considering the growing pressure put on the mining industry facing environmental challenges [6], literature analysis shows how research on quarry planning is mainly dealing with environmental problems. Some studies concentrate on how to assess the impacts associated with the extraction and processing of raw materials so as to prevent, mitigate, 
or remove negative externalities $[7,8]$. Other studies focus on the concept of environmental sustainability and on the critical aspects of quarry planning, which involve a wide range of disciplines $[9,10]$. The issue of determining the use of the land for the post-production phase, so as to recover degraded areas and improve the landscape and biodiversity, seems very relevant [11]. Based on the context within which quarries are inserted, the recovery for natural uses (restoration), as protected areas or mixed-use areas, is taken into consideration, particularly if the quarries are close to already urbanized areas [12]. In urbanized contexts, the importance of participatory approaches to help local administrations in their choices has been proven [13]. To minimize landscape impact while quarrying is going on, progressive recoveries are essential and feasible [14]. To assess naturalistic recoveries' effectiveness, indicators methods [15], also based on a multi-taxa approach [16], have been studied. Some studies have assessed the ecological functioning of quarry lakes [17] and the opportunities for the recovery of those areas as a habitat for birds [18,19]. Other studies have shown how the assessment of ecosystem services can provide guidance to help decision-makers in evaluating alternative recovery scenarios [20].

A minor part of the quarry plan planning processes literature deals with issues of a technical and economical nature. Some studies on the demand drivers of natural aggregates show the connections among the mining, construction, and manufacturing sectors [21]. Other studies on the circular economy have shown that the use of recycled aggregates to substitute natural ones in construction can limit excessive exploitation of raw materials [6,22]. Also the aid of software based on mathematical algorithms is being studied for quarries' long-term planning, and the support provided by Geographic Information Systems (GIS) in quarry planning appears to be relevant in creating geodatabases [23], integrating information coming from studies of other disciplines [24], and creating maps and scenarios to support decisions $[25,26]$.

Analyzing literature about quarry planning, we notice that scientific research has mostly dealt with issues related to environmental sustainability, biodiversity, ecosystem services, recovery, and final use of quarry areas. The relevance of using GIS in database construction and in creating maps to support decisions clearly emerges. Literature also points out the importance of considering recycled aggregates in estimating the demand for raw materials as alternatives to natural ones, while the problems that local authorities have to face in planning have been investigated less. As a matter of fact, it is not clear enough how to assess the most suitable quantity of sand and gravel to be extracted from each quarry. This is a pivotal problem, because this choice has an impact on the environment in which raw materials are. It causes both pressures on the environment and earnings for the mining companies involved. In the Italian case, there are guidelines and rules that provide methodologies for estimating the overall sand and gravel demand of a given territory, but there is a gap in the literature for the allocation of shares in the quarries. Having considered this lack, this study focuses on the planning support technologies that can help decision-making.

Since the 1990s, the scientific community has wondered how to support decisions during the urban or spatial planning processes, also taking advantage of the emerging opportunities provided by the the Geographic Information System (GIS) as a tool to support planning [27]. Studies on the Planning Support System (PSS) highlight that a "system of decision support" must integrate GIS, Multi-criterial Mathematical Models (MMM), or a Multi-criterial Analysis Approach (MAA) with communication/participation tools [28]. PPS "are intended to make the planning process more transparent to a broader range of individuals from a broader spectrum of socioeconomic conditions, through producing information that can be used and understood by a variety of practitioners and stakeholders" [29], and flow of information is managed through informatics. "In this way, urban informatics connects the science of cities to the science of planning and PSS technologies" [30]. As already underlined by Allen, "to help prospective users sort through tool choices, rigorous evaluation of tool capabilities and performance is needed. Such a service, performed by a qualified academic or non-profit professional group, could accelerate tool adoption by 
reducing uncertainties and risks that new users face when selecting tools and encouraging tool developers to pursue best practices'" [31]. Marco teBrömmelstroet proposes a research study focus on performance of PSS and highlights research gaps and the importance of PSS taxonomy (Informing, Communicating, and Analyzing PSS) [32]. Furthermore, in the 21st century, the complexity of PSS traditional technology has been overcome by GIS-based Planning Support technologies [33], and they are actually used in practical planning to inform and improve policies and decisions [34].

This study proposes an Analyzing PSS (GIS-based Planning Support technology) calibrated for sand and gravel quarry planning, providing an advanced modelling tool to support public decision-makers during the planning process. The study will focus on answering the following research questions: Is it possible to assist public authority in defining the proper amount of sand and gravel to be extracted and the dimension of each quarry through a GIS-based Planning Support technology?

\section{Materials and Methods}

The methodological approach of the paper (Figure 1) relies on a four-step linear analysis. The first and fundamental phase is represented by the input data selection to implement the PSS. The input data must be site-specific, and they must be chosen in accordance with the public authority and with the stakeholders involved in the quarry planning process.

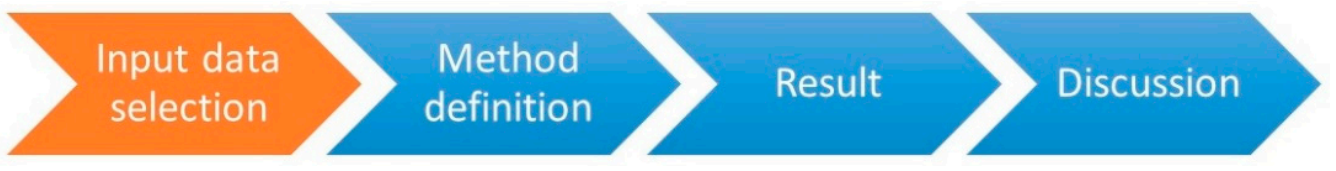

Figure 1. Analyzing PSS approach.

Then, the Analyzing PSS can be set in order to state both the proper amount of sand and gravel to be extracted and the dimension of each quarry. The PPS is applied in a real case study, and the results are presented. In the paper, finally, the discussion reveals the potential and the limitation of the MAA proposed, suggesting recommendations for the authorities (decision-makers) involved in the redaction of a sand and gravel quarry plan.

\subsection{Input Data}

In order to implement an Analyzing PSS and calculate the volume of raw material to be extracted from each quarry, the following data are needed:

1. Estimation of the overall sand and gravel demand. The value is expressed in cubic meters $\left(\mathrm{m}^{3}\right)$.

2. Monitoring database of the previous quarry plan. This includes data on the volumes of raw material to be extracted from each quarry according to the old plan, data on effectively extracted volumes $\left(\mathrm{m}^{3}\right)$, and the quarries' perimeters.

3. Territorial database in GIS. This includes geographical, geological, infrastructural, environmental, and landscape data. The data are acquired from geoportals of public authorities who are competent about the territory, or data can be acquired on the field using on-site inspections. The database also includes existing quarries' perimeters.

4. Data about the mining companies. This includes data about environmental quality certificates, the number of employees, and the availability of plants for the recovery of aggregates in support of the circular economy.

5. Information and data on the mining companies' business development plans. The data can be collected through a survey promoted by the public authority that must prepare the new quarry plan. This information is useful in the decision-making process. 


\subsection{Method}

The goal of the Analyzing PSS is to define the volume of raw material to be extracted from each quarry so as to satisfy the overall sand and gravel demand established in an update of a quarry plan. Overall sand and gravel demand estimation is assumed as input data and is not a goal of the PSS. The PSS proposed and the methodology are applicable in a territory where an upgrade of the sand and gravel quarry plan is needed and is based on five main steps (Figure 2):

1. Exclusion of existing non-exploitable quarries

1.1. Assessment of potentialities of existing quarries

1.2. Exclusion of exhausted or dismissed quarries

1.3. Confirmation of quarries with exploitable deposit

2. Assignment of sand/gravel base volumes (Pre-dimensioning)

2.1. Assignment of "Intermediate Quota" (IQ)

2.2. Assignment of "Base Quota" (BQ) and "Quota s" (Qs)

3. Assignment of sand/gravel premium volumes and overall check

3.1. Assignment of "Premium quota" $(P Q)$

3.2. Assignment of "Maximum Quota" (MQ)

3.3. Assessment of quarries expansion and deepening limitations

3.4. Overall check

4. Reassignment of non-assignable volumes

4.1. Reassignment of volumes to quarries belonging to the same basin (Local Quarries Network)

4.2. Reassignment of volumes to quarries belonging to the same mining company

4.3. Iteration of the process from point 3.3

5. Final volume assignment

5.1. Assignment of "Final Quota" (FQ) to each quarry.

1. Exclusion of existing nonexploitable quarries
1.1. Assessment of potentialities of existing quarries

1.2. Exclusion of exhausted or dismissed quarries

1.3. Confirmation of quarries with exploitable

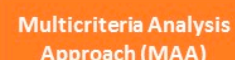

Approach (MAA)

Iteration process

2. Assignment of sand/gravel

base volumes

(Pre-dimensioning)

2.1. Assignment of "Intermediate Quota" (IQ)

2.2. Assignment of "Base Quota" (BQ) and "Quotas" (Qs)

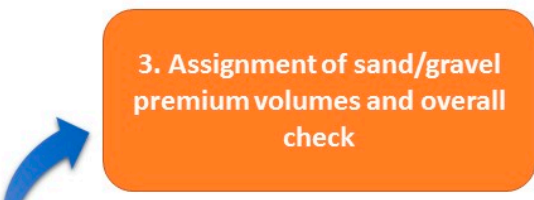

3.1. Assignment of "Premium Quota" (PQ)

3.2. Assignment of "Maximum Quota" (MO)

3.3. Assessment of quarries expansion and deepening limitations

3.4. Overall check

4. Reassignment of nonassignable volumes

4.1. Reassignment of volumes to quarries belonging to the same basin (LQN) 4.2. Reassignment of volumes to quarries belonging to the same mining company 4.3. Iteration of the process from point 3.3

5.1. Assignment of "Final Quota" (FQ) to the quarry

Figure 2. Method flow.

Step 1. An assessment of the potential of existing quarries is carried out. If a quarry has been depleted or if for any reason it is no longer possible to go on extracting raw 
material, the quarry is excluded from the new quarry plan. If conversely, the deposit still is exploitable and there are no critical issues, the quarry is confirmed in the new quarry plan. The assessment is based on the data present in the monitoring database of the previous quarry plan and in the mining companies' survey results.

Step 2. A volume quota called "Base Quota" (BQ) is assigned to each quarry as a fixed percentage of an "Intermediate Quota" (IQ). The IQ is proportional to the volumes assigned to the quarries by the previous quarry plan. Proportionality is calculated both at the single quarry level and also at the Local Quarries Network (LQN) level.

$L Q N$ s are basins, spatially defined, which aggregates quarries according to the relational fields and socio-economic, geographic, historical, and culturally homogeneous features. In quotas allocation, proportionality with the previous plan is maintained to respect former companies' investments, and LQNs are used to maintain the territorial balance. Therefore, the $I Q$ is calculated by the equation below, Equation (1).

$$
I Q_{i}=D \times \frac{\sum_{L Q N} V p q_{i}}{\sum V p q_{i}} \times \frac{V c q_{i}}{\sum_{L Q N} V c q_{i}}
$$

where $D$ is the sand and gravel demand; $V p q$ is the previous quarry plan volume assigned to the single quarry; $V c q$ is the volume assigned by the previous quarry plan in the quarries confirmed by the new plan; and the summation $i$-th is the overall value for all the quarries or the overall value for the quarries included in a single $L Q N$.

Furthermore, the quotas are carried out using a Multi-criteria Analysis Approach (MAA), which requires the input data of the estimated sand and gravel demand data, the monitoring database of the previous quarry plan data, and the territorial database in GIS.

As already explained before, the "Base Quota" (BQ) is a fixed percentage of IQ. The remaining part of $I Q$ constitutes "quota s" $(Q s)$, which is the input data for the estimation of the "Premium Quota" $(P Q)$ in the following step 3. Therefore, the relation among quotas can be synthesized as follows (Equation (2)):

$$
I Q=Q B+Q P f(Q s)
$$

The relation between $Q B$ e $Q s$ is strictly related to the importance of the "premium" given by the decision-maker, so an example of the assigned weight at "base" and "premium" quotas is presented in the case study.

Step 3. A volume quota, called "Premium Quota" $(P Q)$, is assigned to each quarry to balance territorial/environmental constraints with mining business sustainability. The calculation of the $P Q$ is carried out using a Multi-criterial Analysis Approach (MAA). As input data, it requires the estimation from the overall sand and gravel demand data, the monitoring database of the previous quarry plan, the territorial database in GIS, and the data about the mining companies, as well as "quota s", which is the part of the "Intermediate Quota" (IQ) not previously assigned. A score based on territorial/environmental aspects and the mining companies' features becomes the base for assigning $P Q$ and given to each quarry.

Such criteria are described below:

- Territorial/environmental features of where the quarry is. Aspects such as environmental impairment, interference with the ecological network, and interferences with floodable areas due to flooding institutions are assessed. The score is assigned according to a weighted linear function between 0 and 2, taking into account the score given to each feature assessed (high critical issues $=0$, medium critical issues $=1$, low critical issue $=2$ ).

- Internal quarry features. Aspects such as the perception of cultivation activity, the presence of landfills within the quarry area, the presence of degraded situations, the perception of the recoveries and prescribed mitigations, and the accessibility of the quarry are assessed. The score is assigned according to a weighted linear function 
between 0 and 2, taking into account the score given to each feature assessed (high critical issues $=0$, medium critical issues $=1$, low critical issue $=2$ ).

- Mining companies' possession of environmental (ISO 14001), quality (ISO 9001), and safety in the workplace (ISO 45001) certifications. The score is assigned according to Boolean logic (no certificate $=0$, possession of certificate $=1$ ).

- Mining companies' employer number. The score is assigned according to a linear function between 0 (the company with the lowest employee number) and 1 (the company with the highest employee number).

- $\quad$ Presence at the quarry of reusable inert waste plants (to support circular economy). The score is assigned according to Boolean logic (no reusable inert waste plant $=0$, presence of plant $=1$ ).

To assign the "Premium Quota" $(P Q)$ to each quarry, each quarry's score $(P)$ and the sum of the score assigned to all the quarries must be known. To assign a quota that is proportional to the size of the quarry, it is necessary to maintain a proper relation between the assigned base quota $(B Q)$ and the premium one $(P Q)$ to be assigned. The equation below has been used.

$$
P Q_{i}=\frac{Q s_{i} \cdot P_{i} \cdot \sum Q_{i}}{\sum Q s_{i} \cdot P_{i}}
$$

where $P Q$ is the "Premium Quota"; $P$ is the score obtained by the quarry for the territorial/environmental aspects and the mining quota features criteria, $Q s$ is "quota s" coming from the previous step; and the summation $i$-th is the overall value for all the quarries. With equal "Base Quota", a hypothetical quarry to which a high score is attributed will obtain a higher $P Q$ compared to another quarry to which a lower score is attributed. Adding the "Base Quota" (defined in the previous step) to the "Premium Quota", one obtains the volume quota to be extracted from each quarry, called "Maximum Quota" (MQ).

The feasibility of the excavation of MQ for each quarry is then carried out. Any limits to the expansion or deepening of the quarries are also checked. The data for this assessment are selected from the territorial database in GIS and in the results of the survey on the mining companies. Finally, the maximum excavable volume is determined for each quarry. If there are any MQ that exceed the maximum excavable volume, it is necessary to proceed as foreseen in the next step.

In the fourth step, the way to reassign those MQ that cannot be extracted from the deposits of existing quarries is defined. The first possibility is to reassign those quotas (volumes) to the other quarries that belong to the same $L Q N$ using a criterion of proportionality, respecting the "maximum quota" already assigned. Those quarries that can receive those additional volumes (quotas) must have a deposit with a quantity of raw material higher than MQ. A second possibility is to reassign the volumes to other quarries belonging to the same mining company. This second chance may be evaluated by using the mining companies' survey results. In the event that some quarries still have excess volumes, it is necessary to go back to point 3.2 of the method and proceed with the reassignment of excess volumes again.

The reassignment of volumes is based on the data obtained from the previous steps, the data obtained from the mining companies survey, and the data from the territorial database in GIS where the $L Q N$ are spatially defined.

The fifth and last step definitively assigns the proper amount of sand and gravel to be extracted in each quarry, called "Final Quota" (FQ). The assignment of "Final Quota" is based on the data obtained from the previous steps of the method. Each step of the method needs the input of the data selected and collected in the preliminary step of the study. The input data needed in each step of the method are represented in Table 1. 
Table 1. Input data in Analyzing PSS main steps.

\begin{tabular}{cccccc}
\hline Method & Input Data 1 & Input Data 2 & Input Data 3 & Input Data 4 & Input Data 5 \\
\hline Step 1 & & & & \\
\hline Step 2 & & & & \\
\hline Step 3 & & & \\
\hline Step 4 & & & \\
\hline Step 5 & & & \\
\hline
\end{tabular}

All steps, but the first, use the results from previous steps as input data. $\square$ Data is required; $\square$ Data is optional;

Data is not required; Input data 1: estimates of overall sand and gravel demand. Input data 2: database of the previous quarry plan monitoring. Input data 3: mining companies survey results. Input data 4: territorial database in GIS. Input data 5: mining companies' data. Step 1: Exclusion of existing non-exploitable quarries. Step 2: Assignment of sand/gravel base volumes (Pre-dimensioning). Step 3: Assignment of sand/gravel premium volumes and overall check. Step 4: Reassignment of non-assignable volumes. Step 5: Final volume assignment.

\section{Results}

\subsection{Presentation of the Case Study}

The province of Brescia is an administrative district of the Lombardy Region, located in northern Italy, between the Alps and the Po river plain. According to the Statistical regions of the Eurostat Union [35], it is classified as "NUTS level 3", and, from an international point of view, it is considered as the eastern part of the metropolitan area of Milan, which is the most developed in Italy (Figure 3). Statistics show that Brescia is one of the most prosperous provinces in Europe and Italy [36]: it has more than 1.2 million inhabitants, and it is among the most populous provinces in Italy (5th out of 110, Eurostat 2016), with a Gross Domestic Product of 40,806.86 million euro (5th out of 111, Eurostat 2016), which however have a bad performance for air pollution [37] and soil consumption phenomena [38]. A vast deposit of sand and gravel is present in the plain. The raw material is first-rate. Lombardy is the Italian Region in which the highest amount of sand and gravel is extracted $(8,350,000$ cubic meters in $2018,27 \%$ of the national total amount [39]), and Brescia is the Lombard province with the highest number of active quarries [40]. Extraction activities represent $3 \%$ of provincial GDP.

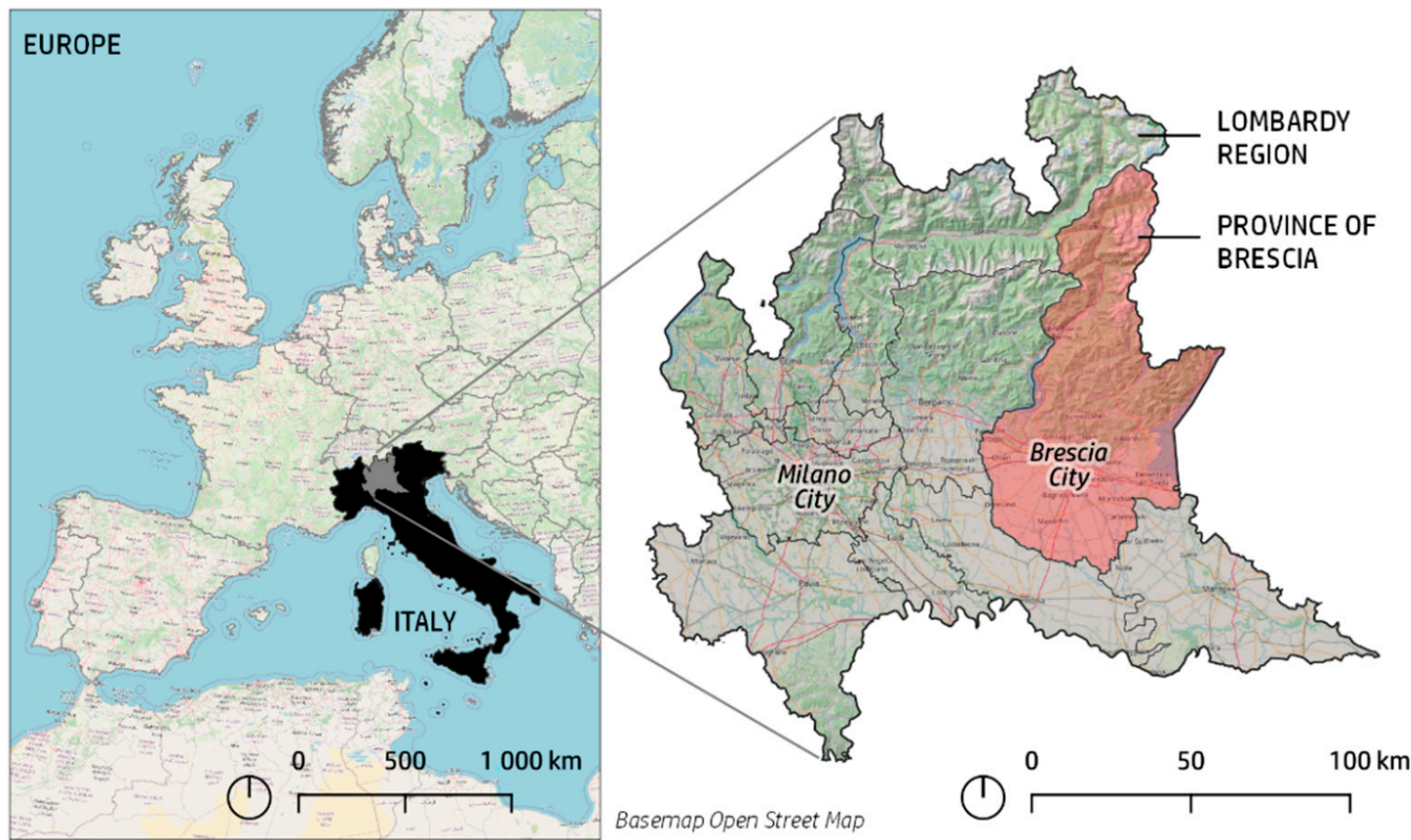

Figure 3. Province of Brescia, area of the study. 
In 2017, the local authority of the Province of Brescia decided to draw up the new Plan for sand and gravel quarries (new PPC), as well as a Strategic Environmental Assessment (SEA). According to Lombardy Regional Law no. 14 of 1998, the plan established the location, quality, and quantity of raw materials as well as the rules for quarrying activities. The plan, valid for ten years, was proposed by provincial authorities and approved by the regional council.

The study case is emblematic in that it concerns one of the Italian provinces that has a very high number of active quarries, a territory with first-rate sand and gravel, and a local public administration that has decided to draw up a new sand and gravel quarry plan.

\subsection{Towards the New Quarry Plan of the Province of Brescia}

The Analyzing PSS has been used to define the volume of raw material to be excavated from each quarry so as to satisfy the overall sand and gravel demand calculated for drawing up the new quarry plan of the Province of Brescia. The input data for the case study are:

1. Estimation of the overall sand and gravel demand for the new quarry plan equal to $46,227,783 \mathrm{~m}^{3}$ for the decade 2018-2028.

2. Previous quarry plan (PPC 2005) monitoring database. It foresaw the quarrying of $64,423,200 \mathrm{~m}^{3}$ in 53 quarries. The source of the data is the Province of Brescia.

3. Territorial database in GIS. The database was built ad hoc starting from public data sources (Region Lombardy geoportal, Province of Brescia geoportal) and integrated after on-site inspections on all quarries active in PPC 2005.

4. Mining companies' data. The database contains data from specialized databases (AIDA Van Dijk, Accredia, consulted in 2020) and information about waste recovery plants (source Province of Brescia).

5. Mining companies' survey results, promoted by the public authority within the Strategic Environmental Assessment of the plan. Seventy-seven responses to the survey were collected.

The overall demand for sand and gravel was estimated using a model provided by the regional deliberation no. 8/11347 of 2010. The application of the case study of the five steps of the Analyzing PSS will be reported in the subparagraphs below.

\subsubsection{Exclusion of Existing No Longer Exploitable Quarries}

In the case of Brescia, the potentiality of the 53 existing quarries, present in the PPC 2005 monitoring database, was assessed. The assessment was also carried out using the results of the mining companies survey. It emerges that 11 quarries out of 53 cannot go on providing sand and gravel. The reason that led to the extension of the quarries are (they may become one or more than one):

- Depletion of the deposit and start of the quarry recovery (nine quarries).

- The mining company could no longer go on extracting raw material from the quarry (four quarries).

- $\quad$ The raw materials present in the deposit are of poor quality (one quarry).

- $\quad$ Therefore, the confirmed quarries are 42.

\subsubsection{Assignment of Sand/Gravel Base Volume (Pre-Dimensioning)}

In the case of Brescia, the BQ is $80 \%$ of $\operatorname{IQ}\left(36,982,226 \mathrm{~m}^{3}\right)$. This percentage was fixed by the decision-maker to gradually introduce the "premium" concept (that consequently is $20 \%$ of $I Q$ equal to $9,245,557 \mathrm{~m}^{3}$ ).

The "Intermediate Quota" (IQ) proportional to the quotas assigned in PPC 2005 was calculated for each quarry. Six $L Q N$ s were identified. $L Q N s$ are expressions of the relational fields, socio-economic, geographic, historical, and culturally homogeneous features, and they coincide with the homogeneous territorial areas already defined by Lombardy Region in the Regional Territorial Plan. To maintain territorial balance and respect companies' investments, the sum of the "Base Quotas" assigned to each LQN by 
PPC 2005 is proportional to the sum of each "Base Quota" assigned to each LQN by the new quarry plan. The shutting down of quarries in a $L Q N$ is compensated by an increased production from the remaining quarries. In the new quarry plan, each $L Q N$ has a variable number of quarries and of assigned volumes (Table 2) based also on territorial features, the presence of sand and gravel, and the accessibility level.

Table 2. Sum of "Base Quotas" (BQ) and quarries for each $L Q N$.

\begin{tabular}{ccc}
\hline LQN & $\boldsymbol{n}^{\circ}$ Quarries * & Volumes $\mathbf{( m}^{\mathbf{3}} \mathbf{)}$ \\
\hline A “Camonica Valley" & 2 & 511,548 \\
B “Trompia Valley and Sabbia Valley" & 3 & $1,023,096$ \\
C "Sebino Franciacorta" & 4 & $3,934,967$ \\
D “Gardesan Riviera" & 3 & $1,260,023$ \\
E "Hills and high Brescia plain" & 21 & $24,334,790$ \\
F “Low Brescia plain" & 9 & $5,917,802$ \\
\hline
\end{tabular}

${ }^{*}$ present until step $n^{\circ} 3$.

\subsubsection{Assignment of Sand/Gravel Premium Volumes and Overall Check}

In the case of Brescia, "Premium Quotas" $(P Q)$ were calculated both on a reward score and on "s quotas" (calculated in the previous step).

For what concerns the premium gain, a score from 0 to 7 based on five criteria was assigned. For the two territorial criteria, scores from 0 to 4 were assigned, while for the three company criteria, scores from 0 to 3 were assigned. In the case in which more than one company operates in a quarry, the score was calculated for each mining company and it was then weighed on the amount of volumes foreseen by the authorization issued to each company.

The choice was to give greater importance to territorial features than to companies' ones.

In the case of Brescia, a total of 137.69 scores were assigned. For what concern "s quotas", they were calculated to maintain a ratio of proportionality with the quarries dimension (indirectly through the proportionality with the "Base Quota"). The sum of "s quotas" was $9,245,557 \mathrm{~m}^{3}$, which is $20 \%$ of the sand and gravel demand estimate. To apply Equation (3) to the case study, it was also necessary to calculate the value of the sum of the results deriving from the multiplication between "s quotas" values and score values assigned to each quarry. This value, equal to 30,503,782, was used as the denominator to maintain a correct relationship between the BQ assigned and the $P Q$ to be assigned. To assign the $P Q$ to each quarry, the following equation was applied.

$$
P Q=\frac{Q s_{i} \times P_{i} \times 9,245,557 \mathrm{~m}^{3}}{30,503,782}
$$

The "Premium Quotas" distributed in LQN are shown in Table 3.

Table 3. Sum of quarries "Premium Quotas" $(P Q)$ for each $L Q N$.

\begin{tabular}{ccc}
\hline LQN & $\boldsymbol{n}^{\circ}$ Quarries * & Volumes $\mathbf{( m}^{\mathbf{3}} \mathbf{~}$ \\
\hline A “Camonica Valley" & 2 & 118,983 \\
B “Trompia Valley and Sabbia Valley" & 3 & 243,143 \\
C "Sebino Franciacorta" & 4 & $1,194,892$ \\
D “Gardesan Riviera" & 3 & 335,437 \\
E “Hills and high Brescia plain" & 21 & $6,041,339$ \\
F "Low Brescia plain" & 9 & $1,311,763$ \\
\hline
\end{tabular}

* present until step $n^{\circ} 3$.

Adding the "Base Quota" (defined in the previous step) to the "Premium Quota", we have the volume quota to be extracted from each quarry, called "Maximum Quota" (MQ). The feasibility of MQ was then checked for each quarry. 
In the case study, a series of criticalities regarding the constraints of enlargement and deepening of the existing quarries were detected following the surveys and supported by existing territorial database evidence in GIS. Such constraints are both to the nature of the deposit and to the coexistence of environmental pressures caused by other activities with an impact on the territory, particularly by landfills and airport activities (Montichiari airport development Plan). Therefore, after the overall check (point 3.4 of the method), $n^{\circ} 4$ quarries were not confirmed, and 12 others were deemed not expandable in width and depth.

\subsubsection{Reassignment of Non-Assignable Volumes}

In the study case, a share equal to $4,664,865 \mathrm{~m}^{3}$ of the volume $(\sim 10 \%$ of the total) could not be extracted in the assigned quarries. Such volumes were reassigned to other quarries belonging to the same $L Q N$ in the following cases:

- In LQN A “Camonica Valley". 20,547 m3 from a quarry were reassigned;

- In LQN E "Hills and high Brescia plain", 3,913,757 m3 from three quarries were reassigned;

- In LQN F “Low Brescia plain”, 730,561 m3 from a quarry were reassigned.

In the case study, it was not possible to extract all the assigned quotas from $L Q N \mathrm{~A}$ quarries owing to territorial and morphological conditions (Piedmont area, river valley). The exceeding volumes, equal to $65,909 \mathrm{~m}^{3}$, were redistributed to quarries belonging to all the LQNs.

The results of the mining companies' surveys highlighted the opportunity for seven quarries to transfer $4,780,968 \mathrm{~m}^{3}(\sim 10 \%$ of the total) to quarries owned by the same company.

\subsubsection{Final Volume Assignment}

The FQ distributed in 38 quarries are shown in Table 4.

Table 4. Sum of quarries' "Final Quota” (FQ) for each LQN.

\begin{tabular}{ccc}
\hline LQN & $\boldsymbol{n}^{\circ}$ Quarries & Volumes $\left(\mathbf{m}^{\mathbf{3}}\right)$ \\
\hline A “Camonica Valley" & 2 & 620,000 \\
B “Trompia Valley and Sabbia Valley" & 3 & $1,370,000$ \\
C "Sebino Franciacorta" & 3 & $3,320,000$ \\
D “Gardesan Riviera" & 3 & $1,739,000$ \\
E “Hills and high Brescia plain" & 20 & $32,375,000$ \\
F "Low Brescia plain" & 7 & $6,790,000$ \\
\hline
\end{tabular}

Figure 4 shows the territorial features of the LQNs (at the top) and a scheme of the Analyzing PSS applied to the case study of Brescia (at the bottom). 

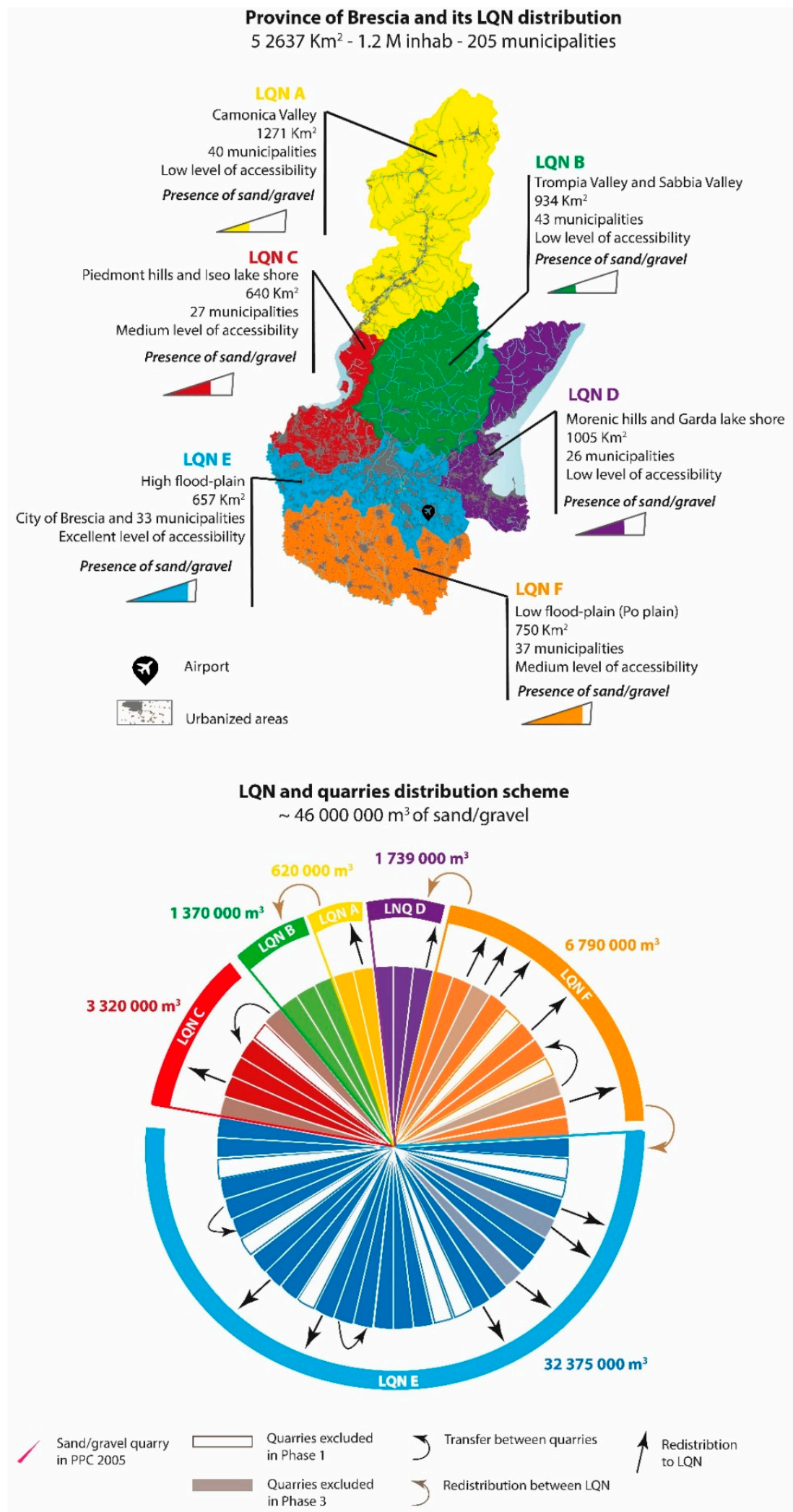

Figure 4. Synopsis of the Analyzing PSS applied to the Brescia case study.

\section{Discussion}

The proposed Analyzing PSS is usable also without a previous plan; in fact, the previous plan monitoring database can be replaced by the simulation of the distribution of volumes in existing quarries or in not yet exploited deposits. 
The assigning of a "Premium Quota" is the innovative part of the methodology, as it leads to reflection on the duality of the quarrying action concerning its public interest: on one hand the provision of raw materials, on the other the protection of the environment. The quantitative criterion of proportionality is functional not to excessively change the size of available deposits and to ensure a balanced supply of material throughout the territory: quarrying will go on less in a small deposit than in a very large one. Additionally, the proportionality criterion guarantees business continuity to those companies that have made investments by installing extraction and processing plants for raw materials.

Furthermore, it must be underlined that "the extractive industry of sand, gravel and rock differs in at least two important aspects from most other industrial sectors. First, the location of the industry and the quality of the material produced are determined by geology in relation to areas of high demand, i.e., large cities. Second, the success of the sector is dependent on the success and competitiveness of the downstream industries. Economic success, therefore, is controlled by two factors: quality and quantity of deposits of natural resources for aggregates and the political, legal, administrative, social, and economic environment in which extraction takes place (Wagner/Tiess, 2004: 27). For both reasons, aggregate companies are used to taking a long-term perspective" [41].

The premium boosts mining companies' proper behavior. LQN identification is a strength, because it allows the balancing of the response for territorial needs, according to the actual availability of the deposits. From the theoretical point of view, considering $L Q N$, the distribution of volumes reduces the negatives deriving from the transport of raw materials. The presence of $L Q N$ when redistributing volumes favors a fair distribution on the territory of the quotas of excavable volumes.

Among the limits, the Analyzing PSS requires an ad hoc structured database. The preliminary step of selecting and acquiring the base information is particularly toilsome. Since it is an iterative method, to reach the definition of the "Final Quota" assigned to each quarry, it is necessary that each step is faced and resolved, as each variation affects the whole system.

In the proposal of the new plan, 38 quarries were confirmed to satisfy a demand of $\sim 46,000,000 \mathrm{~m}^{3}$ of primary sand and gravel (input data 1 and 34\% lower than PPC 2005), no new quarries were planned, and sixteen quarries were cancelled. Among the 38 confirmed quarries, nineteen were expanded and eight were reduced.

The construction of the new plan allowed an important shift from the traditional planning process to a GIS-based Analyzing PSS approach based on MAA.

In the case of Brescia, defining the $L Q N$ causes severe limitations due to the criteria with which the units were defined: they are only partially based on territorial and socioeconomic features (such as urban density, self-contained labor market, population size, and accessibility) in favor of corporate nature agreements. Therefore, political geography prevails over economic geography. Additionally, the political decision-maker did not demand setting limits to quarries' expansion where there is an exploitable quality deposit: it would have been advisable to identify maximum limits in the volume redistribution mechanism, so as to avoid excessive pressures on the territory and excessively large areas.

\section{Conclusions}

The objective of this study was to understand if it is possible to assist the public authority in defining both the proper amount of sand and gravel to be extracted and the size dimension of each quarry. This goal can be achieved through the application of the proposed GIS-based Planning Support technology. However, we must be aware that the final performance of the Analyzing PSS is affected by decision-maker choices and conditioned by economic interests at the regional level. Planning action is complex and subject to economic and environmental pressures. In the case of raw materials quarrying, economic interests (both mining companies' ones and in relation to the economy of the sector) often prevail over environmental protection. A non-trivial pressure is represented by the induced activity in the labor sector, where in the case study, the quarries represent 
$3 \%$ of the provincial GDP. Environmental pressure is determined by the concentration of quarry activities due to the raw materials in the subsoil. In Italy, such impacts are partially offset by the charge on aggregates (to compensate for the environmental costs caused by a quarry, and to protect the landscape) that "is only one element of a very complex planning, authorization, and regulation system related to quarrying activities" [41].

Finally, the proposed PSS does not automatically build alternative scenarios from which to choose the best one, but it implies making political decisions during the various steps. The Analyzing PSS objectifies volumes' assignment, but it implies a well-defined governing direction. In the study case, the decision-maker's choice to identify a percentual of the total premium quote equal to $20 \%$ of the sand and gravel demand did not allow the adequate exploitation of the premium potentiality.

Author Contributions: Conceptualization, M.P.; methodology, M.P. and A.R.; software, F.C.P.; validation, M.P. and A.R.; investigation M.P., A.R., and F.C.P.; data curation, F.C.P.; writing-original draft preparation, M.P., A.R., and F.C.P.; writing-review and editing, M.P., A.R., and F.C.P.; visualization, A.R.; supervision, M.P.; All authors have read and agreed to the published version of the manuscript.

Funding: This research was funded by Provincia di Brescia, "Cooperation agreement between Brescia University and Province of Brescia for the definition of the provincial mining needs and the structuring of the proposed new Quarry Plan for sand, gravel and clay product sector", 2017.

Institutional Review Board Statement: Not applicable.

Informed Consent Statement: Not applicable.

Data Availability Statement: Restrictions apply to the availability of these data. The data are not publicly available due to the cooperation agreement submitted by authors with the Province of Brescia.

Conflicts of Interest: The authors declare no conflict of interest.

\section{References}

1. New Zealand Aggregate \& Quarry Association Fact Files. Available online: https://www.aqa.org.nz/industry/fact-files/ (accessed on 24 February 2021).

2. Li, J.; Zhang, J.; Ni, S.; Liu, L.; Walubita, L.F. Mechanical performance and environmental impacts of self-compacting concrete with recycled demolished concrete blocks. J. Clean. Prod. 2021, 293, 126129. [CrossRef]

3. Sverdrup, H.U.; Koca, D.; Schlyter, P. A Simple System Dynamics Model for the Global Production Rate of Sand, Gravel, Crushed Rock and Stone, Market Prices and Long-Term Supply Embedded into the WORLD6 Model. Biophys. Econ. Resour. Qual. 2017. [CrossRef]

4. United Nations Environment Programme. Sand and Sustainability: Finding New Solutions for Environmental Governance of Global Sand Resources; United Nations Environment Programme: Geneva, Switzerlands, 2019.

5. European Aggregates Association. Annual Review 2018-2019; UEPG: Brussels, Belgium, 2019.

6. Ruokonen, E. Managerial perspectives on strategies for advancing environmental considerations in the mining industry. Extr. Ind. Soc. 2020, 8, 434-441. [CrossRef]

7. Careddu, N.; Siotto, G. Promoting ecological sustainable planning for natural stone quarrying. The case of the Orosei Marble Producing Area in Eastern Sardinia. Resour. Policy 2011. [CrossRef]

8. De Oca Risco, A.M.; Carcassés, M.U.; Cruz, S.G.; Castañeda, A.L.S. Environmental mining indicators for the determination of degradation in quarries through Geographic Information Systems. An. Geogr. la Univ. Complut. 2020. [CrossRef]

9. Laurence, D. Establishing a sustainable mining operation: An overview. J. Clean. Prod. 2011, 19, 278-284. [CrossRef]

10. Lechner, A.M.; McIntyre, N.; Witt, K.; Raymond, C.M.; Arnold, S.; Scott, M.; Rifkin, W. Challenges of integrated modelling in mining regions to address social, environmental and economic impacts. Environ. Model. Softw. 2017, 93, 268-281. [CrossRef]

11. Wilker, J.; Rusche, K.; Benning, A.; MacDonald, M.A.; Blaen, P. Applying ecosystem benefit valuation to inform quarry restoration planning. Ecosyst. Serv. 2016, 20, 44-55. [CrossRef]

12. Milgrom, T. Environmental aspects of rehabilitating abandoned quarries: Israel as a case study. Landsc. Urban Plan. 2008, 87, 172-179. [CrossRef]

13. Pietta, A.; Tononi, M. Re-Naturing the City: Linking Urban Political Ecology and Cultural Ecosystem Services. Sustainability 2021, 13, 1786. [CrossRef]

14. Martín Duque, J.F.; Tejedor, M.; Martín Moreno, C.; Nicolau, J.M.; Sanz Santos, M.A.; Sánchez Donoso, R.; Gómez Díaz, J.M. Geomorphic landscape design integrated with progressive mine restoration in clay quarries of Catalonia. Int. J. Min. Reclam. Environ. 2020, 5, 1-22. [CrossRef] 
15. Zhang, Q.; Zhang, T.; Liu, X. Index system to evaluate the quarries ecological restoration. Sustainability 2018, 10, 619. [CrossRef]

16. Mexia, T.; Antunes, C.; Nunes, A.; Mira, A.; Correia, A.I.; Serrano, A.; Correia, O. Beyond the green: Assessing quarry restoration success through plant and beetle communities. Restor. Ecol. 2020, 28, 971-978. [CrossRef]

17. Seelen, L.M.S.; Teurlincx, S.; Bruinsma, J.; Huijsmans, T.M.F.; van Donk, E.; Lürling, M.; de Senerpont Domis, L.N. The value of novel ecosystems: Disclosing the ecological quality of quarry lakes. Sci. Total Environ. 2021, 769, 144294. [CrossRef]

18. Day, G.; Mayes, W.M.; Wheeler, P.M.; Hull, S.L. Can aggregate quarry silt lagoons provide resources for wading birds? Ecol. Eng. 2017, 105, 189-197. [CrossRef]

19. Rohrer, Z.; Rebollo, S.; Monteagudo, N.; Talabante, C. Eagle Owl presence and diet at mining sites: Implications for restoration and management for cliff-nesting birds. Restor. Ecol. 2020, 28, 1541-1550. [CrossRef]

20. Calvo Robledo, A.; MacDonald, M.A.; Butt, C. Restoration scenario planning at a Spanish quarry can be informed by assessing ecosystem services. Restor. Ecol. 2020, 28, 1006-1013. [CrossRef]

21. Auci, S.; Vignani, D. Mines and quarries production: A driver analysis of withdrawals in Italy. Resour. Policy 2020, 67, 101657. [CrossRef]

22. Balletto, G.; Mei, G.; Garau, C. Relationship between quarry activity and municipal spatial planning: A possible mediation for the case of Sardinia, Italy. Sustainability 2015, 7, 16148-16163. [CrossRef]

23. Bottero, M.C.; Polo Pérez, I.; Taddia, G.; Lo Russo, S. A geodatabase for supporting planning and management of mining activities: The case of Piedmont Region. Environ. Earth Sci. 2020, 79, 1-12. [CrossRef]

24. Santos, I.; Sousa, L.; Lourenço, J. Granite resource evaluation: Example of an extraction area in the north of Portugal. Environ. Earth Sci. 2018, 77, 1-14. [CrossRef]

25. Barakat, A.; Ouargaf, Z.; Touhami, F. Identification of potential areas hosting aggregate resources using GIS method: A case study of Tadla-Azilal Region, Morocco. Environ. Earth Sci. 2016, 75, 774. [CrossRef]

26. Bottero, M.; Ferretti, V.; Pomarico, S. Assessing different possibilities for the reuse of an open-pit quarry using the choquet integral. J. Multi-Criteria Decis. Anal. 2014, 21, 25-41. [CrossRef]

27. Huxhold, W.E. An Introduction to Urban Geographic Information Systems; Oxford University Press: New York, NY, USA, 1991; ISBN 0195065344.

28. Schifani, C. Modelli di Conoscenza e Processi Decisionali; University IUAV: Venice, Italy, 2010.

29. Pan, H.; Deal, B. Reporting on the Performance and Usability of Planning Support Systems-Towards a Common Understanding. Appl. Spat. Anal. Policy 2020, 13, 137-159. [CrossRef]

30. Pan, H.; Chen, S.; Gao, Y.; Deal, B.; Liu, J. An urban informatics approach to understanding residential mobility in Metro Chicago. Environ. Plan. B Urban Anal. City Sci. 2020, 47, 1456-1473. [CrossRef]

31. Allen, E. Clicking toward Better Outcomes: Experience with INDEX, 1994 to 2006. In Planning Support Systems for Cities and Regions; Brail, R.K., Ed.; Lincoln Institute of Land Policy: Cambridge, UK, 2008; pp. 139-166. ISBN 978-1-55844-182-8.

32. Te Brömmelstroet, M. Performance of Planning Support Systems: What is it, and how do we report on it? Comput. Environ. Urban Syst. 2013, 41, 299-308. [CrossRef]

33. Pan, H.; Geertman, S.; Deal, B. What does urban informatics add to planning support technology? Environ. Plan. B Urban Anal. City Sci. 2020, 47, 1317-1325. [CrossRef]

34. Page, J.; Mörtberg, U.; Destouni, G.; Ferreira, C.; Näsström, H.; Kalantari, Z. Open-source planning support system for sustainable regional planning: A case study of Stockholm County, Sweden. Environ. Plan. B Urban Anal. City Sci. 2020, 47, 1508-1523. [CrossRef]

35. Eurostat. Statistical Regions in the European Union and Partner Countries; Publications Office of the European Union: Luxembourg, 2020; ISBN 978-92-76-10625-8.

36. Eurostat. Eurostat Regional Yearbook; Publications Office of the European Union: Luxembourg, 2020; ISBN 978-92-76-20728-3.

37. EEA. Air Quality in Europe-2019 Report; Publications Office of the European Union: Luxemburg, 2019; ISBN 978-92-9480-088-6.

38. EEA; FOEN. Urban Sprawl in Europe; Publications Office of the European Union: Luxemburg, 2016.

39. ISTAT. Le Attività Estrattive da Cave e Miniere. Available online: https://www.istat.it/it/archivio/246015 (accessed on 29 March 2021).

40. Regione Lombardia Cave per Provincia e Materiale Estratto sul Territorio Lombardo. Available online: https://www.dati. lombardia.it/Ambiente/Cave-per-Provincia-e-Materiale-Estratto-sul-Territ/2usm-qiua (accessed on 29 March 2021).

41. EEA. Effectiveness of Environmental Taxes and Charges for Managing Sand, Gravel and Rock Extraction in Selected EU Countries-European Environment Agency; Office for Official Publications of the European Communities: Luxemburg, 2008. 